\title{
EL DERECHO COMO FORMA DE LA POLÍTICA Y DE LA SOCIEDAD*
}

\author{
Enrique Barros \\ Universidad de Chile
}

\begin{abstract}
Resumen: En este ensayo se asume el rol esencial de las instituciones en la configuración de la vida en sociedad. Nuestra debilidad y ventaja radica en gran medida en una naturaleza biológica indeterminada, que nos abre a la exploración y a la acumulación de experiencia. Sin embargo, a su debilidad constitutiva es atribuible que el ser humano sea capaz de las conductas más despiadadas. En contraste, investigaciones etnográficas comprueban que el ser humano responde a arquetipos relacionales muy fuertes, como son la reciprocidad y rituales de pacificación.

Aunque las instituciones se expresan en formas de vida que sólo excepcionalmente se forman por medio de una decisión reflexiva, poseen, a la vez, un sustrato de racionalidad y de adaptación a los instintos. Tampoco su observancia requiere de una particular racionalización. Por eso, actúan como una especie de gramática de nuestra vida de relación.

El derecho ha sido objeto de atención por las más diversas doctrinas políticas y morales. Sin embargo, mientras las ideas
\end{abstract}

Enrique Barros. Abogado. Profesor de derecho, Universidad de Chile. Miembro del Consejo Directivo del CEP.

* Texto ampliado de la conferencia dada el 28 de septiembre de 2011 en el ciclo "Formas de la realidad" organizado por el Centro de Estudios Públicos. 
filosóficas o políticas expresan la apertura del ser humano a la crítica y al cambio, sólo cuando se transforman en derecho se hacen carne como instituciones. El derecho moderno da forma a la política y al mismo tiempo tiene por función domesticarla. De hecho, cumple funciones muy diversas, especialmente en una sociedad de la complejidad de la moderna.

La posibilidad de cambio hace del derecho el más dinámico de los ordenamientos de conducta. La certeza es una función esencial del derecho, lo que explica que la forma le sea un elemento distintivo. Buena parte de las instituciones jurídicas más relevantes suponen un cierto grado de formalismo, desde la democracia como criterio de atribución del poder hasta las clásicas instituciones de resguardo de los derechos. Por eso, el desprecio de la forma, especialmente en sede judicial, supone privar al derecho de sus funciones sociales más importantes, particularmente como resguardo de la libertad.

Palabras clave: derecho, instituciones, sociedad, formas de vida.

\section{LAW AS THE FORM OF POLITICS AND SOCIETY}

Abstract: In this essay it is hold that institutions play an essential role in shaping the life of a society. As human beings, our weaknesses and advantages lie in great measure in a biologically determined human nature, which opens us to exploration and accumulation of experience. However, on account of their constitutive weakness, human beings are capable of the most wretched acts. By contrast, ethnographic research has showed that human beings also respond to strong archetypes in their relationships, as those of reciprocity and peacemaking rituals.

Though institutions express ways of life that only exceptionally develop by thoughtful decision making processes, they do possess a basis of rationality and of adaptation to instincts. They do not require special reasoning for compliance either. They are thus a sort of grammar of our relations with one another.

Diverse political and moral doctrines have paid attention to law. Philosophical or political ideas express the openness of human beings to criticism and change, but it is only when they are converted into law that they also become flesh as 
institutions. Modern law both shapes and tempers political life. Indeed, law performs many different functions, especially in complex modern societies.

The possibility of change makes law the most dynamic directive of human behavior. To provide certainty is one of its distinctive and essential functions. Many of the most relevant legal institutions require some degree of formalization, from democracy as a criterion to confer powers, to classical institutions for the protection of rights. So the disdain of form, in particular by law courts, deprives the law of one of its more important social functions, especially for the preservation of freedom.

Keywords: law, institutions, society, ways of life.

\section{I}

Q n esta charla intentaré primeramente delinear algunas ideas acerca de la función de las instituciones en nuestra vida social. He convivido por muchos años con estas nociones, tanto que cuando vuelvo a ellas me revive el asombro intelectual de la juventud. Sobre la base de ese concepto funcional de las instituciones haré luego una breve reflexión sobre el derecho como una institución que da forma a la vida en sociedad. Concluiré argumentando que esta función es consistente, a su vez, con una lógica interna del derecho que supone un significativo grado de formalidad.

El derecho que rige nuestras relaciones más diversas no es un don de nuestra naturaleza biológica, sino una creación de la cultura. Es una institución humana. Tenemos una disposición básica a la sociabilidad y somos capaces de juicio moral como fue mostrado hace veinticuatro siglos por Aristóteles. El lenguaje no sólo nos permite razonar y referirnos a la realidad que nos rodea, sino también articular juicios acerca de la belleza de expresión artística, de la experiencia de Dios o de las notas distintivas de la virtud. En otras palabras, desde una cierta perspectiva el ser humano puede alcanzar altos grados de racionalidad y modos muy sutiles de sensibilidad.

Pero nuestra especie también puede desarrollar los comportamientos más despiadados. Algunos justificados por el interés más 
egoísta, pero también por las ideas aparentemente más altruistas, como ha ocurrido con los más diversos fundamentalismos laicos o religiosos en el último siglo. Tanto para desarrollar nuestras potencias virtuosas como para mantener a raya las destructivas necesitamos de instituciones que sean en cierto sentido ciegas a nuestras subjetividades; y que en cierto sentido las domestiquen.

Temprano los hombres desarrollaron una cierta sociabilidad al interior de la estirpe familiar y de la comunidad tribal. Investigaciones sobre los nuer, un pueblo que vive al sur del Sudán y que fue escrutado científicamente en un estado originario en los años 30 del siglo pasado, muestran una sociabilidad soportada por un delicado tejido institucional. Las relaciones al interior de la tribu son ordenadas sobre la base de fuertes lazos de reciprocidad en los intercambios y de retribución del daño. Los daños de cualquier tipo producidos al interior de la tribu dan lugar a la venganza fundada en un deber de retribución. Desde niños los nuer son educados en el valor. Están así preparados para enfrentar disputas o para vengar una muerte que compromete a todo el clan. En el extremo, incluso una muerte casual puede terminar en una masacre.

Para evitar los efectos desoladores de la venganza, los nuer desarrollaron reglas orientadas a neutralizar la violencia. Un rol esencial en la prevención del conflicto es jugado por el 'hombre de la piel de leopardo', el sacerdote de la tierra, quien presta protección temporal al victimario. Su casa es un lugar sagrado. Se evita así que la retribución espontánea comprometa a los clanes familiares involucrados. Mientras el victimario está bajo protección, se inicia un largo período de tiempo en que los ánimos se temperan. La venganza de la sangre es sustituida por una negociación dirigida por el sacerdote de la tierra, que busca una reciprocidad compensatoria. Luego de un primer rechazo ritual de cualquier indemnización económica, la negociación suele terminar con la entrega de cierto número de cabezas de ganado a la familia de la víctima ${ }^{1}$.

El modelo de apaciguamiento parece repetirse en otros pueblos. Isak Dinesen, en sus hermosas Memorias de África, narra cómo ella misma se vio envuelta en una negociación compensatoria que siguió a la muerte de un niño por un disparo que casualmente salió de una escopeta manipulada por un joven de otra estirpe. En África, dice

1 E. E. Evans-Pritchard, The Nuer: A description of the modes and political institutions of a Nilotic people [1940] 1969, pp. 152 ss. 
Dinesen, no hay otra forma de reaccionar frente a una muerte que no sea la restitución: a la muerte, muerte; cualquiera sea la causa, casual o voluntaria. Sin embargo, para evitar el derramamiento de sangre, se reúne por semanas el consejo de ancianos hasta encontrar alguna reparación en equivalencia, y para que el tiempo calme entretanto los ánimos de venganza que arrastrarían a toda la comunidad ${ }^{2}$.

En otras palabras, parece haber ciertas constantes institucionales, aun a falta de una administración de justicia especializada, para dar forma a la retribución social justificada por el hecho de sangre. Así y todo el equilibrio es precario como lo muestran hasta hoy las matanzas por disputas tribales que se desencadenan como relámpago.

El derecho dictado por la autoridad y no sustentado en la costumbre nace más bien tarde. El más antiguo vestigio es el Código de Hamurabi, de la Babilonia del s. XVIII a.C., que recoge la jurisprudencia de su época e influyó en el desarrollo de todo el derecho mediterráneo posterior, incluso en el hebreo y el romano ${ }^{3}$. En occidente, las XII Tablas, una ley promulgada en los orígenes de la república en Roma (s. V a.C), consagra derechamente el talión, salvo acuerdo compensatorio. Así de claro. Una especie de simetría de las acciones inspira el derecho a la venganza, a menos que se acuerde otra compensación.

Pero el paso más importante de la época romana parece haber sido el establecimiento de "acciones con las que los hombres pudieran pleitear entre sí, las cuales, para que el pueblo no las practicara a su arbitrio, quisieron que fueran determinadas y solemnes". Estas acciones judiciales pasan a ser las únicas formas legítimas de hacer valer los derechos, como se ha transmitido hasta nuestros días ${ }^{4}$. Los orígenes del derecho en nuestra tradición cultural podrían situarse en este vigoroso período republicano de la antigua Roma.

En definitiva, la humanidad ha creado el derecho como una forma cultural evolucionada, ante el abismo de una naturaleza proclive al desborde desencadenado por una subjetividad que se eriza con facilidad. El ser humano carece de los instintos fuertes de los animales superiores. Nuestra agresividad es constitutiva y nos puede llevar a fronteras de crueldad que no conocen los animales. Hobbes estaba en verdad

${ }^{2}$ I. Dinesen, Memorias de África [1937] 1969, pp. 99 ss.

${ }^{3}$ Código de Hamurabi (traducción y estudio preliminar Federico Lara), 1986.

${ }^{4}$ Pomponio, Digesto, 1.2.2.6. 
equivocado cuando decía que el hombre en un estado de naturaleza es un lobo respecto de sus semejantes: el lobo, a diferencia del hombre, tiene fuertes restricciones instintivas para atacar a sus congéneres y sólo mata animales de otras especies en defensa o para comer.

La muchedumbre, como mostró Elías Canetti en Masa y poder ${ }^{5}$, ese hermoso ensayo que penetra en las profundidades de la asociatividad humana, tiene comportamientos imprevisibles e irracionales y puede adquirir las conformaciones más diversas. Esta precariedad de grupos humanos entregados a sí mismos ha sido reiteradamente ilustrada por la literatura. Es el caso de El señor de las moscas de William Golding, esa obra escalofriante acerca de la pérdida de la inocencia de un grupo de niños que quedan aislados luego de la caída del avión que los transportaba. Pronto se desarraigan de las formas de vida más bien dulces y domésticas en que habían estado inmersos y quedan entregados a crear por sí mismos un orden de convivencia. Terminan en un horrible estado de naturaleza hobbesiano de división y agresividad destructiva. En el otro extremo, en Expiación de Ian McEwan, el desamparo y lucha despiadada por sobrevivir de los militares aliados que llegan a la playa huyendo de los alemanes en Dunkerke; se trata de hombres especialmente instruidos para sobrevivir gracias a la colaboración recíproca, aun en las circunstancias más adversas, pero una vez perdidas las coordenadas sociales que aseguraban su cohesión, caen en el abismo del egoísmo más desenfrenado.

Más cerca en nuestra experiencia, perdidos los controles sociales fuimos testigos de la reacción violenta o carroñera ante el sentimiento de abandono institucional que se vivió en muchos lugares después del terremoto del año 2010; o en la civilizada Vancouver, donde jóvenes desencantados se pueden transformar en turba descontrolada y destructora luego de la pérdida de una final de hockey sobre hielo; y así sucesivamente.

Pero esa misma agresividad ha contribuido a que el hombre haya avanzado a lo largo de las generaciones: aumentando el conocimiento e innovando gracias a la curiosidad y apertura al mundo, descubriendo nuevas formas de relacionarse, desarrollando nuevos intereses y valores por los que vale la pena jugarse. La agresividad nos hace seres abiertos a la experiencia fáctica y moral, a explorar lo desconocido y a ampliar nuestra sociabilidad y los intercambios; somos inventores de nuestras

${ }^{5}$ E. Canetti, Masa y poder (traducción Horst Vogel) [1960] 1981, p. 7 ss. 
vidas y de relaciones con los demás ${ }^{6}$. Esa actitud abierta a los demás es decisiva también en nuestra sociabilidad: "el hombre despojado de todo lo que llamamos animal, privado de los impulsos misteriosos y convertido en puramente razón, no sería un ángel, sino todo lo contrario"7. Con su insuperable agudeza Aristóteles nos definió precisamente como animales racionales, porque sólo así se da cuenta de nuestra compleja constitución que nos acerca y diferencia de los animales superiores ${ }^{8}$.

El lugar del derecho en la sociedad se muestra en ambas dimensiones: cumple la doble función de dar forma a las relaciones humanas patológicas y cooperativas. Su carácter institucional se muestra en la manera natural en que es observado y en la forma en que actúa como justificación de nuestra conducta. Para entender la función institucional del derecho en una sociedad crecientemente diferenciada basta atender a que es característico de las instituciones que dirijan nuestra conducta sin necesidad de dar razones adicionales. Su debilitamiento deja al descubierto nuestra flaqueza estructural. No estamos simplemente constituidos para actuar sólo con nuestro programa biológico y sin embargo éste nos es constitutivo. Nuestra razón práctica se condensa en instituciones de cuya eficacia e importancia ni siquiera solemos ser conscientes.

\section{II}

He señalado que las instituciones no sólo son funcionales a apaciguar y encauzar la conducta en situaciones patológicas, sino también expresan nuestra natural disposición a la comunicación y al intercambio. $\mathrm{Y}$ esta es su función positiva, mucho más amplia y, en cierto sentido, invisible. El sentido básico de reciprocidad en nuestra vida de relación, que la filosofía moral ha llamado justicia correctiva o conmutativa, es la base más profunda de las interacciones sociales en pueblos primitivos, como muestra Malinowski en un precioso estudio sobre las sociedades de las islas Tobriand al noreste de Nueve Guinea ${ }^{9}$.

${ }^{6}$ K. Lorenz, Sobre la agresividad, ese pretendido mal (traducción Félix Blanco y Armando Suárez) [1963] 1981, Cap. XIII, p. 260 ss.

${ }^{7}$ Ibídem, p. 289.

${ }^{8}$ Aristóteles, Política I. 2 (1253a 2-3).

9 B. Malinowski, Crimen y costumbre en la sociedad salvaje [1926], 1978, p. 61 ss. 
Lo más importante en nuestra vida de relación cotidiana son maneras compartidas de pensar y de actuar que difícilmente pueden ser interpretadas a la luz de nuestra razón planificadora, sino del desarrollo espontáneo de nuestra vida en común. La más característica de estas instituciones es el lenguaje. La ciencia ha mostrado que el lenguaje tiene su base en capacidades innatas ${ }^{10}$; pero se desarrolla en una práctica de comunicación sumamente compleja (esto es, una institución). Más contemporáneamente, formas espontáneas de asociatividad, que la tecnología ha potenciado, como twiter y facebook, han creado paso a paso su propia legalidad cultural.

Wittgenstein, en algunos de sus más profundos aforismos, se refiere a las instituciones como formas compartidas de vida, que no requieren de justificación como directivas de nuestra conducta. Así se explica que cuando uno es preguntado por qué observa una regla sea una respuesta natural 'simplemente porque así lo hacemos nosotros' ${ }^{\text {'1 }}$.

En el campo de acción del derecho, cuando observamos una norma del tránsito no necesitamos justificar la acción ni la regla. Y si alguien nos pregunta por qué pasamos sin detenernos cuando el semáforo está en verde, la respuesta aceptada como correcta en nuestros usos puede resultar tautológica: 'porque el semáforo estaba en verde'. Para observar la regla no necesitamos racionalizar nuestra conducta; ni menos aún, en el caso del derecho, racionalizar el complejo mecanismo de validación de las normas en un ordenamiento complejo que nos hace tener por obligatoria la regla que establece que el semáforo en verde significa que la vía está libre.

Estas ideas se expresan en el derecho en el concepto de validez: la norma legal, administrativa o contractual vale porque ha sido generada de acuerdo con un procedimiento para la creación de directivas previsto por el propio derecho. Esta validez está soportada, además, por la fuerza institucionalizada. Preguntarse por la legitimidad de ese procedimiento supone salirse del juego (en lo que no hay ningún juicio moral, sino meramente institucional). Por eso, desde un punto de vista

${ }^{10}$ N. Chomsky, Problems of knowledge and freedom, 1971 (tomado de edición alemana, Über Erkenntnis und Freiheit, 1973, p. 12 ss.).

11 L. Wittgenstein, Philosophische Untersuchungen (Investigaciones filosóficas), $§ \S 217$ ss. 
analítico, la validez del derecho supone ${ }^{12}$, o bien se asienta $^{13}$ en una regla que expresa la aceptación generalizada de un orden normativo como derecho.

Malinowski observa empíricamente respecto de las costumbres de los pueblos melanesios que investigó: "El salvaje siente una reverencia profunda por la tradición y las costumbres, así como muestra una sumisión automática a sus mandatos [...] El salvaje está muy lejos de ser la criatura libre y despreocupada que nos pinta la imaginación de Rousseau"14. Al fin de cuentas el salvaje no está tan lejos de nosotros. Sólo que entre los melanesios no existía un poder central que tuviera potestades para dictar reglas generales en un proceso constante; no había un poder legislativo ni uno regulatorio; el derecho estaba indiferenciado de las costumbres. Pero, al final de cuentas, no era tan diferente la forma en que ejercía su fuerza obligatoria.

\section{III}

En muchos de estos sentidos el derecho moderno tiene sus raíces en el derecho romano. En un estado avanzado de la república, el pretor, un alto funcionario, publicaba al comenzar su mandato un edicto donde señalaba las reglas a las que se sometería la administración de justicia. Aunque originalmente el edicto se renovaba ex nihilo todos los años, se desarrolló la costumbre de que el pretor dictara un edicto traslaticio, en cuya virtud los edictos anteriores se incorporaban a su propio edicto. El pretor podía modificar las reglas, derogarlas o introducir nuevas, pero

${ }^{12}$ H. Kelsen, Reine Rechtslehre, 1960, p. 223 ss. Kelsen pone énfasis en la segunda edición de su teoría pura del derecho de la función teoréticocognoscitiva de la norma fundamental, de modo que es un mero presupuesto lógico-trascendental y carece de pretensión alguna de validez. Es interesante que la norma fundamental, en esta doctrina positivista radical, permita asumir la validez, lo que permite comprender el derecho como un orden normativo, que, sin embargo, carece de todo fundamento material. Así se logra que la teoría se relacione con un orden normativo que efectivamente rige y cuyos contenidos son por completo contingentes.

${ }^{13}$ H. L. A. Hart, The concept of law, 1994, esp. p. 94 ss. Es interesante que el formalismo neokantiano de Kelsen sea sustituido en Hart por una regla que está validada por una práctica de observancia. La influencia del tardío Wittgenstein no puede ser más evidente, en mi opinión. 1978, p. 22.

14 B. Malinovski, Crimen y costumbre en la sociedad salvaje [1926], 
no partía de nuevo cada vez. De este modo, en la república romana se estableció un procedimiento para que el derecho fuera creado y se fuera consolidando con la práctica traslaticia, de la manera que nos resulta usual en el mundo moderno. Fue una gran innovación, muy en línea con el espíritu práctico de la cultura jurídica romana ${ }^{15}$.

En paralelo, el derecho aplicable a los casos era dictado por juristas, que no fallaban los conflictos, sino daban con la regla aplicable. El derecho privado, de esta manera, pasó a ser un sistema de reglas altamente diferenciadas y crecientemente abstractas; adquirió un grado de desarrollo y de refinamiento técnico que lo hizo, a la vez, general y formalizado.

Lo característico del derecho radica en que los cambios, incluso los referidos a paradigmas más esenciales, son generalmente progresivos. Así ocurre, por ejemplo, en el derecho privado moderno, caracterizado por una consideración menos abstracta de la autonomía privada, que se hace cargo de abusos en contratos masivos, de contratos en que una parte posee una posición de dominio de mercado, del engaño por silencio u ocultamiento, y de relaciones asimétricas entre expertos y legos. La expansión de una cultura jurídica más atenta a la realidad de los intercambios, más que a paradigmas demasiado abstractos, se corresponde con cambios en la manera de mirar las relaciones económicas interpersonales en una cultura política y social más reflexiva respecto de las desigualdades. Estos cambios producen efectos en las doctrinas jurídicas tradicionales en una dialéctica de tradición y cambio. Así, el derecho, tanto el privado como el público, posee una fuerte base cultural que es el sustento integrador del dinamismo alcanzado por la máquina regulatoria en que ha devenido el estado moderno ${ }^{16}$.

El protagonismo de la ley y de las decisiones administrativas es efectivamente un cambio importante del derecho contemporáneo. Desde esta perspectiva, el derecho es un ordenamiento dinámico, en que antiguas leyes y reglamentos pueden ser derogados o modificados

$15 \mathrm{Ph}$. Nemo, Histoire des idées politiques dans l'Antiquité et le Moyen Âge, 2007 (1998), Parte 2a, p. 324 ss (esp. 399 ss.). Del mismo autor puede verse la sección sobre el derecho como aporte de Roma a la tradición occidental en ¿Qué es el Occidente? [2004] 2006.

${ }^{16}$ De ahí la importancia de las 'partes generales' del moderno derecho civil y administrativo, que se hacen cargo de asegurar la inteligibilidad de los cambios normativos a la luz de una doctrina jurídica que los tematiza y se renueva a sí misma. 
y nuevas reglas pueden ser introducidas. A diferencia de otros ordenamientos normativos, el derecho establece procedimientos para su autogeneración mediante el proceso político. Desde un punto de vista lógico no existe tanta diferencia con lo que hacía el pretor en la república romana; sólo que la velocidad y complejidad de las normas, especialmente de las regulaciones administrativas, no conoce precedentes. Este es el trasfondo real de las doctrinas analíticas del derecho.

El derecho es una poderosa institución en una sociedad en extremo diferenciada como la actual. Tiene el cimiento que da una tradición puesta a prueba por la experiencia y la razón, pero al mismo tiempo tiene una estructura procedimental que permite a los titulares del poder público su permanente cambio y adaptación. Pero, recíprocamente, el derecho no sólo legitima el poder, sino también tempera y domestica el uso de la fuerza, en el ámbito público o privado.

Hablando de la importancia del derecho en la temprana democracia norteamericana, Tocqueville observaba que el derecho es el efectivo contrapeso al poder, incluido el de la mayoría. Advierte que

los hombres que han hecho un estudio especial de las leyes han sacado de esos trabajos hábitos de orden, un cierto apego a las formas, una especie de amor instintivo por el encadenamiento regular de las ideas, que les hacen naturalmente opuestos al espíritu revolucionario y a las pasiones irreflexivas de la democracia ${ }^{17}$.

Tocqueville veía en el derecho (y en el lugar que las profesiones legales tenían en la nueva república) un contrapeso frente a los riesgos a la libertad provenientes de una democracia naciente, que estaba dotada de una legitimidad política sin precedentes. En otras palabras, el espíritu jurídico que empapó tempranamente a la democracia norteamericana era visto por Tocqueville como el contrapeso esencial del poder legitimado desde la base.

El poder expansivo del estado moderno es moderado por el derecho mediante las instituciones que limitan y domestican el ejercicio del poder. En este sentido más elemental, el derecho da forma a la sociedad política: determina cómo se obtiene y pierde el poder, lo distribuye, Cap. VIII.

${ }^{17}$ A. de Tocqueville, La democracia en América [1848] 1980, 1ª Parte, 
define las facultades que tiene cada cual y somete a reglas su ejercicio. Por eso, desde un punto de vista jurídico, también la democracia constitucional es una forma del $\operatorname{poder}^{18}$.

No es extraño que todos los principales filósofos morales y políticos hayan puesto su atención en el derecho. Desde Tomás de Aquino hasta Habermas, desde los filósofos y economistas liberales hasta los modernos pensadores sociales funcionalistas o utilitaristas; todos ellos han visto en el derecho un orden que colinda o está en el corazón de sus reflexiones filosóficas y políticas. La razón de este interés se encuentra en que no hay idea que se refiera a aspectos esenciales de la vida de relación que finalmente no aspire a transformarse o a ser tematizada por el derecho.

La filosofía política discute si el derecho es un instrumento de seguridad que nos permite salir de la anarquía, constituyendo un poder público que nos protege a unos de otros (como en Hobbes); cautela la propiedad (como en Locke y Hume); posibilita los intercambios espontáneos en un orden sujeto a reglas (como en la tradición de Adam Smith hasta Hayek); es garantía exterior de la libertad entendida como presupuesto de la moralidad (como en Kant); materializa principios de justicia política (Rawls); maximiza el bienestar (como en el análisis económico del derecho); expresa la formación legitima de opinión y de voluntad de ciudadanos que tienen iguales derechos (como en Habermas); o si expresa esencialmente un orden de preceptos que pueden ser obtenidos por medio de la razón práctica y procuran el bien común (como contemporáneamente en Finnis y en la tradición aristotélica del derecho natural).

Pero lo cierto es que el derecho cumple, o puede cumplir, todas estas funciones y satisfacerlas en distintos grados a la vez. Lo que agrega el derecho a nuestra vida en sociedad es su arquitectura. Por eso, la función del derecho como regla general de convivencia es inseparable de la forma. Cualquiera sea la función o sentido al que se atienda, un cierto formalismo le es necesario.

${ }^{18}$ E. Barros, "La democracia como forma del poder", 1987, p. 1 ss. 
Esta atención se enraíza en una intuición fundamental: las ideas sólo se encarnan cuando adquieren forma institucional. Por sí solas no son capaces de cambiar la sociedad ni de dirigir la conducta en sociedad. Las ideas anteceden a los cambios, los inducen; pero por sí solas no los provocan.

Las manifestaciones estudiantiles de 2011 lograron poner en discusión graves problemas, que estaban latentes, en germinación, en parte escondidos tras un velo de ignorancia colectivo. Aunque por vocación he pretendido mantenerme consciente de que la educación contribuya al crecimiento de personas que sean dueñas de sí mismas, de modo que la sociedad sea más vivible y justa, reconozco que pertenezco al enorme grupo de chilenos que por años hemos actuado como 'imbéciles felices'. La educación tiene que ver con el encadenamiento de las generaciones, donde los padres están preocupados con lo que ocurrirá con sus hijos. Cada generación tiene responsabilidades respecto de la que le sigue. Y esa tarea se ha cumplido mediocremente, considerando nuestras posibilidades como sociedad.

Pero todas estas ideas y propuestas se marchitan si no adquieren la forma de políticas públicas. Los problemas de financiamiento, de calidad, de integración, de igualdad de oportunidades en nuestra educación deben traducirse en leyes de presupuesto, en instituciones de gobierno con poderes y capacidades suficientes para ejecutar las políticas públicas, en estímulos económicos a los establecimientos educacionales y a las familias, en formas organizacionales que garanticen buen gobierno a los colegios y universidades, y así sucesivamente. Pero todo ello supone formas institucionales. Sólo con instituciones bien diseñadas esta generación puede hacerse cargo virtuosamente de que la próxima viva en una sociedad más justa, sensible y abundante. Las ideas y los buenos propósitos sirven de detonante y de estímulo, pero requieren del derecho para transformarse en conductas.

Al final de cuentas, el derecho da forma y adquiere forma de la política. Imaginemos un ambiente de discusión pública permanente carente de cauces institucionales. Ante todo, no sería imaginable que sólo sobre esa sola base existiera un sistema educacional de la complejidad del existente. Por mediocre y por acompañado de carroña que sea, éste ha permitido progresos sustanciales en una generación. Tampoco habría caminos para avanzar hacia un sistema de educación que cumpla al menos algunos de los nuevos o mejores estándares que se proponen. 
De la mano de las puras ideas, muchas de ellas contradictorias entre sí, no es posible lograr un ordenamiento que en su conjunto sea más justo y eficiente. Al final de cuentas, las ideas motivan cambios jurídicos, pero requieren del derecho para ser duraderas; del mismo modo como las religiones requieren de la liturgia y las amistades de prácticas recíprocas de lealtad que las sostengan en el tiempo.

La forma sigue a la función decía Henry Sullivan, el gran arquitecto modernista. En el derecho la forma es consustancial a sus funciones sociales más básicas. Uno de los principales aportes del positivismo jurídico analítico (en la tradición de Austin, Kelsen y Hart) a la comprensión del derecho es haber destacado la forma como una característica estructural, especialmente del derecho moderno.

\section{V}

Desde el punto de vista de los bienes en juego, conviene también tener presente que los principios de justicia no son los más exigentes. La justicia misma es una virtud que sólo nos exige de nuestra razón práctica lo básico y necesario para convivir de manera recíprocamente decente y fructífera. La justicia no exige un particular heroísmo, como es el llamado cristiano al amor. Por eso, puede decirse que es la virtud del ciudadano, a quien no se le exige ser un héroe ni un santo. $Y$ es sintomático que el derecho se asocie a la justicia, esto es, a la directiva más elemental requerida en nuestra vida de relación.

Pero también la justicia supone su formalización en reglas. En su concepto más básico, la justicia es formal porque exige tratar igual casos iguales. Por eso, las reglas que organizan el poder y definen nuestros derechos y deberes en una sociedad política bien constituida deben ser generales. Mientras la caridad es una invocación a nuestras facultades morales superiores, la justicia es una medida de igualdad y distribución, como ya lo tuvo claro Aristóteles ${ }^{19}$. Y es medida porque no exige más que lo que resulta exigible en nuestra vida de relación. Es sintomático que el límite moral del derecho esté dado por la justicia y no por la caridad.

${ }^{19}$ Ética a Nicómano, Libro V (1129a ss.). 


\section{VI}

Una de las doctrinas más influyentes en el pensamiento moral contemporáneo es la del discurso, que implica una teoría consensual de la verdad y exige que toda regla sea capaz de superar la prueba de un debate público dirigido a la materialización de una verdad comunicativa. Las condiciones de este debate son fuertes, porque a nadie que aspira lealmente a lograr un acuerdo que sea universal le es permitido argumentar legítimamente a partir de intereses o creencias especiales (Habermas, Appel). De hecho, la libertad de expresión y la explosión de medios técnicos de comunicación instantánea han hecho que ese debate público se desenvuelva de una manera descentralizada y multifocal, comprendiendo los intereses más dispares.

El problema surge cuando esas posiciones encontradas deben traducirse en una regla común de convivencia. Son tantas las variables en juego y las diferencias en las preferencias que nada permite presagiar que de ese debate, por leal que sea, surjan acuerdos vinculantes para todos.

Desde luego que el debate público es una forma especialmente calificada de participación. De hecho, una de las ventajas de ese discernimiento público es poner temas sobre la mesa, expresar preferencias y proponer caminos de solución. Es también el medio para que se exprese en la comunidad ese sentido moral proteico que caracteriza nuestra naturaleza. Pero es tarea del derecho el diseño final. La historia no es moldeable sólo a partir de ideas generales, del mismo modo como las revoluciones no crean un orden por sí mismas. La realidad no se presta para una refundación institucional a la luz de un modelo platónico ideal y perfeccionista. La misma historia nos enseña que el desenlace de tales intentos suele ser deplorable, lo que explica que las revoluciones devengan en un resultado político por lo general tan alejado de lo que prometen.

La necesidad de jerarquizar, tanto razones como medios, pone límites muy próximos a la transformación directa de ideas valorativas en reglas de convivencia. Los valores o ideales tienen que ser sopesados en concreto para que puedan dar lugar a un conjunto transitivo de preferencias. Y esa es una tarea muy ardua y de incierto desenlace. Por el contrario, las reglas de derecho tienden a estar codificadas de manera binaria, como válidas e inválidas. En este punto se muestran las ventajas y también las limitaciones del derecho. 
El derecho es una institución pública estructurada básicamente en la forma de reglas. Especialmente en nuestro tiempo, en que la creación de normas en la forma de regulaciones es un proceso continuo, el derecho no puede ser explicado como una transformación directa por derivación de ideales e intereses comunes en normas. En una democracia constitucional, como es la estructura básica de nuestro sistema jurídico-político, la mayor garantía de participación es el procedimiento de elección de autoridades; recíprocamente este procedimiento legitima el ejercicio del poder público. También tienen carácter procedimental las reglas que permiten tener por conformada la voluntad política ${ }^{20}$.

Por cierto que la libertad de conciencia y de expresión son esenciales en el impulso y desarrollo del fenómeno político. El derecho suele ser el resultado de una deliberación pública más o menos amplia. Pero no siempre es posible encontrar soluciones que hagan compatibles las opiniones o cosmovisiones en juego. Aunque se asuma un punto de vista neutral, que evite tomar partido en cuestiones ampliamente discutidas, como lo propone Habermas, resulta inevitable hacerlo en el proceso de creación de derecho. Otras veces, tal vez la mayoría, la discusión no se resuelve desde una perspectiva abstracta, puramente normativa, y es necesario tomar partido.

Por eso, por ejemplo, aunque las políticas educacionales deben ser tan neutrales como sea posible a las diferentes perspectivas valóricas que coexisten en la sociedad, la decisión práctica (en el sentido clásico, de la regla correcta de conducta) requiere en decenas de materias (financiamiento, control, de calidad, contenidos, organización de los colegios, distribución del presupuesto entre distintos niveles educacionales) de una ponderación de bienes en juego que no puede ser validada por un consenso racional abstracto.

A eso se agrega que la discusión en todas las materias políticas más importantes no está confinada a la ordenación de los bienes en juego, sino tiene componentes extremadamente técnicos. Las reglas son el producto (output) de ese proceso político y administrativo. Las ideas y propósitos se deben transformar en legislación. Este es el supuesto condicionante de la incorporación de ideales al sistema legal que efectivamente rige la vida en sociedad.

${ }^{20}$ Esa es la tesis de N. Luhmann, Legitimation durch Vefahren, 1975, en especial Cap. III, p. 137 ss. 
Por cierto que el propio derecho ha desarrollado una lógica interna en sus diversas disciplinas, cuyas fuentes más remotas se encuentran en el derecho privado romano, en el constitucionalismo democrático y en los principios del gobierno sujeto a la ley. A su vez, el derecho contemporáneo está marcado por desarrollos que atienden a principios de justicia material, que no sólo se expresan en el derecho público (subsidios, servicios públicos gratuitos), sino también en estatutos especiales de protección en las relaciones privadas (trabajadores, consumidores, inversionistas, deudores financieros, por ejemplo).

Sin embargo, estos principios adquieren vigencia institucional en la medida que devienen en directivas más concretas. Lo relevante para quien aplica el derecho no es el conjunto informe de argumentos o expectativas prejurídicas. En el centro de la actividad (legítima) de adjudicación judicial no está el discurso moral, sino la regla legal.

Los jueces carecen de los instrumentos analíticos para decidir acerca de las políticas públicas. Estas suponen decisiones que son también políticas, esto es, basadas en criterios pragmáticos generales y sujetas a un proceso especial de deliberación a nivel legislativo o administrativo. Hay una diferencia estructural entre juzgar de acuerdo a una regla preexistente y legislar. Para el juez suelen ser inconmensurables las razones con que lidia el legislador. Baste imaginar un sistema educativo que no responda a políticas públicas expresadas en reglas que persigan materializar ideales de equidad, de calidad y de eficiencia de la educación, sino se construya caso a caso sobre la base de apreciaciones difusas de los jueces acerca de lo que es bueno o correcto.

En estos límites de la transformación de las ideas en derecho se muestra que a este subyace naturalmente un cierto formalismo. Por eso, la estructura de legitimaciones públicas en una democracia constitucional no autoriza a los jueces para devenir en protagonistas del proceso regulatorio. Y si los jueces encuentran que no hay una solución inequívocamente correcta, de igual modo deben honestamente fundar su decisión desde el derecho. Pero aun en ese caso es sintomático que las sentencias innovadoras tienden a transformarse en precedentes, aun en sistemas de derecho legislado. Lo contrario sería contrario a la justicia en sentido formal, que exige igual solución para casos iguales.

Desde un punto de vista funcional, el derecho en una sociedad compleja es un subsistema cuya función es establecer programas de 
conducta $^{21}$. Esta función supone que existan límites a la argumentación relevante ante un tribunal. No cualquier argumento es aceptable en una disputa legal. Por lo demás, esa es una condición para que las interacciones sociales estén regidas por reglas y no por las inclinaciones o preferencias de los jueces. Los jueces no actúan en nombre propio sino como órganos de una comunidad política que les asigna una función esencial pero limitada 22 .

Desde Adam Smith hasta Jorge Millas, en muy diferentes generaciones y tradiciones intelectuales, ha resultado claro que el derecho es insustituible en la función de dar certeza acerca del orden básico de convivencia, de concretizar ideas normativas que de lo contrario no estarían preparadas para transformarse en instituciones capaces de regir nuestra vida en sociedad.

Por cierto que todo ello con el límite de que en un estado constitucional democrático el derecho no pretende comprender toda nuestra vida social, como se muestra en nuestras relaciones más íntimas sean de amistad, de familia o de comunidades afectivas, que pertenecen a un espacio libre de regulación legal (y a la inversa, están protegidas por un imperativo de legitimidad).

Llegamos así a la distinción entre el derecho y la moral, que ya he avizorado en las notas anteriores. En uno de los textos más duros del Nuevo Testamento, Jesús se refiere a los hipócritas que "purificáis el plato y la copa por fuera, mientras por dentro estáis llenos de rapiña y de maldad" (Lc. 11,20). El hipócrita cumple el derecho, aunque actúe sin convicción moral alguna. El derecho positivo es heterónomo y sólo califica la conducta exterior, porque no puede penetrar en el interior de la conciencia ${ }^{23}$.

${ }^{21}$ La más ponderosa teoría funcionalista de la positividad del derecho en N. Luhmann, "Positivität des Rechts als Voraussetzung einer modernen Gesellschaft" [1970], en: Ausdifferenzierung des Rechts. Beiträge zur Rechtssoziologie und Rechtstheorie, 1999, p. 113 ss.

22 J. Raz, Between authority and interpretation, 2009, Cap. 13, con referencia al supuestamente más abierto de los estatutos jurídicos, como es la interpretación constitucional.

${ }^{23}$ I. Kant, "Introducción a la metafísica de las costumbres", tomado de la traducción española de las secciones I a IV, incluida en I. Kant, Introducción a la teoría del Derecho [1797] 1978, p. 52 ss. 
Por lo mismo, su validez está socialmente fundada en el reconocimiento y en su aplicación efectiva. Su normatividad es precaria en ese sentido. Pero también allí radica su fortaleza.

Por lo mismo, todo sistema jurídico desarrollado también supone grados significativos de formalidad en su propio método. La norma de derecho se compone de un supuesto de hecho y de una consecuencia: si doy mi consentimiento, cumpliendo tales y cuales requisitos, debo cumplir lo prometido; si manejo con algunas copas de más, me multarán y me suspenderán la licencia; si causo daño por mi descuido, debo indemnizarlo; y así sucesivamente. Un sistema jurídico que escape a ese modelo deontológico (sometido a reglas) y opte por una amplia discrecionalidad basada en un sopesamiento desestructurado de valores o fines en conflicto no cumpliría su función de dar forma a las relaciones sociales. Ahí también se encuentran los límites de un concepto del derecho y de la política que pretenda comprender la tarea del jurista como la de un filósofo moral.

Es sintomático de esta realidad que los principios jurídicos que garantizan la sujeción del poder público y privado al derecho asuman un cierto formalismo como principio constitutivo, llámese estado de derecho, rule of law o constitucionalismo democrático (los términos no son sinónimos, pero pertenecen a la misma familia de conceptos). En todos los casos el derecho debe seguir un criterio público de promulgación y exige que toda autoridad (especialmente el juez) se rija por las reglas constitucionales y legales que definen su función.

Así se explica una larga tradición jurídica en cuya virtud la tarea del juez es adjudicar, esto es, decir el derecho de cada cual sobre la base de una regla preexistente. El derecho, como dice uno de los grandes juristas del siglo pasado, no es jugar a lo que decida el árbitro, sino es un juego sujeto a reglas que el árbitro debe respetar, interpretar y aplicar $^{24}$. En definitiva, el formalismo es simplemente consistente con su función.

Pero el formalismo del derecho es también garantía de libertad. En palabras de Jhering: "Enemiga jurada de la arbitrariedad, la forma es hermana gemela de la libertad. Es, en efecto, el freno que detiene las tentativas de aquellos que arrastran la libertad hacia la licencia; la que dirige la libertad, la que la contiene y la protege. Las formas son la es-

${ }^{24}$ H. L. A. Hart, The concept of law [1994] 1997, p. 141 ss. 
cuela de la disciplina y el orden, y por consiguiente de la libertad. [...] El pueblo que profesa verdadero culto a la libertad comprende instintivamente el valor de la forma, y siente que ella no es un yugo exterior, sino el vigía de la libertad" 25 .

Es bien sintomático que toda dictadura siempre aspire a desatarse de las restricciones que imponen las formas desarrolladas por el derecho. Y, por el contrario, aunque uno no lo racionalice de esa manera, se tienda a admirar las sociedades donde el derecho prevalece como forma del poder y de la convivencia en la sociedad civil. En esas sociedades es aún posible una vida heroica; pero no a costa de la libertad de los demás para desarrollar su propio plan de vida.

\section{REFERENCIAS}

Aristóteles. Ética a Nicómano. Gredos. Politica. Gredos.

Barros, E. "La democracia como forma del poder". Estudios Públicos 26 (1987).

Canetti, E. Masa y poder. Traducción de Horst Vogel. Barcelona: Muchnik [1960] 1981.

Chomsky, N. Über Erkenntnis und Freiheit. Frankfurt: Suhrkamp, 197. [Edición en inglés, Problems of knowledge and freedom, 1971].

Código de Hamurabi: Traducción y estudio preliminar Federico Lara. Madrid: Tecnos, 1986.

Dinesen, I. Memorias de África. Madrid. Alfaguara: [1937] 1969.

Evans-Pritchard, E. E. The Nuer. A description of the modes and political institutions of a Nilotic people. New York i.a.: Oxford University Press, [1940] 1969.

Golding, William. El señor de las moscas [1954]. Edhesa.

Hart, H. L. A. The concept of law. Editada por P. Cane, T. Honoré y J. Stapleton. Oxford: Clarendon Law Series, 1994, 2da edición.

Jhering, R. von. El espiritu del Derecho Romano en las diversas fases de su desarrollo. Madrid: Bailly-Bailliere, s/f. [Edición francesa de O. de Meulenaere, 1877].

Kant, I. "Introducción a la metafísica de las costumbres". En I. Kant, Introducción a la teoría del Derecho (traducción F. González V.) Madrid: Centro de Estudios Constitucionales, [1797] 1978.

Kelsen, H. Reine Rechtslehre. Viena: Deuticke, 2a edición, 1960.

${ }^{25}$ R. von Jhering, El espíritu del Derecho Romano en las diversas fases de su desarrollo (traducido desde la edición francesa de O. de Meulenaere, 1877), s/f, p. 180. 
Lorenz, K. Sobre la agresividad, ese pretendido mal. Traducción de Félix Blanco y Armando Suárez. México: Siglo XXI, 11ª edición [1963] 1981.

Luhmann, N. Legitimation durch Vefahren. Darmstadt: Luchterhand, 1975. "Positivität des Rechts als Voraussetzung einer modernen Gesellschaft” [1970]. En Ausdifferenzierung des Rechts. Beiträge zur Rechtssoziologie und Rechtstheorie. Frankfurt: Suhrkamp, 1999.

Malinowski, B. Crimen y costumbre en la sociedad salvaje. Barcelona: Ariel, [1926] 1978.

Mc Ewan, Ian. Expiación. Anagrama, 2002.

Nemo, Ph. Histoire des idées politiques dans l'Antiquité et le Moyen Âge. Paris : Quadrige/PUF, 2007 (1998),

¿Qué es el Occidente? Madrid: Gota a Gota, [2004] 2006.

Pomponio, Digesto.

Raz, J. Between authority and interpretation. Oxford: Oxford University Press, 2009.

Tocqueville, A. de. La democracia en América. Madrid: Alianza, [1848] 1980.

Wittgenstein, L. Philosophische Untersuchungen. Frankfurt: Suhrkamp, 2003. 